\title{
INDOOR VOC CONCENTRATIONS AT NURSERY AND PRIMARY SCHOOLS: IMPACT OF COVID-19 PREVENTIVE MEASURES
}

\author{
JULIANA P. SÁ, PEDRO T. B. S. BRANCO, MARIA C. M. ALVIM-FERRAZ, \\ FERNANDO G. MARTINS \& SOFIA I. V. SOUSA \\ Laboratory for Process Engineering, Environment, Biotechnology and Energy (LEPABE), \\ Faculty of Engineering, University of Porto, Portugal
}

\begin{abstract}
The importance of evaluating indoor air pollutants, such as volatile organic compounds (VOC), became a topic of utmost interest, especially during COVID-19 pandemic due to the increasing cleaning and disinfection of hands, surfaces and spaces, the most common measures to prevent the spread of COVID19. VOC presence in indoor environments can impair human health, particularly above threshold limit values. Thus, this study aimed to quantify the differences between VOC concentrations before and during COVID-19 pandemic in indoor air of one nursery and one primary school in Porto, Portugal. This study was carried out in early 2020 (before COVID-19 pandemic) and early 2021 (during COVID19 pandemic) in two classrooms - I07_A (nursery school) and S07_B (primary school). Both classrooms presented a similar school timetable between the two periods, but the personal and environmental hygiene throughout the day using alcohol-based sanitisers were hugely increased in 2021. Total VOC (TVOC) were monitored continuously with research-grade instruments for a minimum period of two consecutive weekdays. Two average periods were considered: (i) an average day period (hourly means of all weekdays); and (ii) an average occupancy period (hourly means during occupancy periods considering the school timetable). Descriptive statistical analysis, as well as normality (Shapiro-Wilk Test) and significance (Wilcoxon Signed Rank Test) tests were performed using the R software version 4.0.5. The statistical significance level considered was set to 0.05 . TVOC concentrations exceeded the limit value in the Portuguese legislation $\left(1,200 \mu \mathrm{g} / \mathrm{m}^{3}\right)$ during occupancy period in both classrooms during COVID-19 pandemic, although they never exceeded before the pandemic. Moreover, a statistically significant increase $(p$-value $<0.05)$ on TVOC concentrations from 2020 to 2021 were observed in the two studied classrooms for both average day (mean difference: $647 \mu \mathrm{g} / \mathrm{m}^{3}$ and $1,170 \mu \mathrm{g} / \mathrm{m}^{3}$ for I07_A and S07_B, respectively) and average occupancy periods (mean difference: $521 \mu \mathrm{g} / \mathrm{m}^{3}$ and 2,730 $\mu \mathrm{g} / \mathrm{m}^{3}$ for I07_A and S07_B, respectively). Therefore, it was possible to conclude that the continued use of alcohol-based products, as a result of COVID-19 prevention measures, could increase TVOC concentrations to unsafe levels in schools.
\end{abstract}

Keywords: indoor air quality, school, VOC, COVID-19 pandemic.

\section{INTRODUCTION}

Children constitute a sensitive population to environmental contaminant's exposure, such as indoor air pollutants, since their lungs and immune system are still under development and they have a relatively higher amount of air inhalation. Moreover, schools are the most important indoor environment for children, apart from home, where they spent a significant part of their time [1]. Effectively, evidence has been made that indoor air pollution (IAP) impacts children's respiratory health [2]. Particularly, the presence of volatile organic compounds (VOC) in indoor environments can impair human health with both acute and chronic effects, especially above threshold limit values [3].

With the outbreak of COVID-19 pandemic declared in March 2020, followed by a general lockdown and closing of schools until September 2020, the Portuguese authorities, following the World Health Organization (WHO) recommendations, adopted a contingency plan for safe reopening of schools with some measures to prevent the spread of COVID-19. The most 
common measures included the frequent hand hygiene using alcohol $70 \%$ sanitisers, as well as the maintenance of a clean environment by disinfection of surfaces and shared objects using sodium hypochlorite solution with a concentration of $0.05 \%$ or alcohol products at $70 \%$ (mostly for surfaces that do not support sodium hypochlorite) as well as improving ventilation [4], [5]. Those products are potentially relevant sources of VOC in indoor environments [6]. Therefore, the COVID-19 pandemic, and particularly the application of preventive measures, reinforced the importance of evaluating indoor air pollutants, such as VOC, making it a topic of utmost interest.

Quantifying the impact of COVID-19 preventive measures on indoor air quality (IAQ) in schools is still quite a recent topic, thus information is still scarce, and particularly the impact on VOC concentrations has not been studied. Thus, this study mainly aimed to quantify the differences between VOC concentrations before and during COVID-19 pandemic in one nursery and one primary school in Porto, Portugal.

\section{METHODOLOGY}

This study was carried out in one classroom from a nursery school (I07_A) and one classroom from a primary school (S07_B), both part of the SENSINAIR project. Both schools are located in urban context in Porto district, North of Portugal $\left(41^{\circ} \mathrm{N}, 8^{\circ} \mathrm{W}\right)$, next to a road with high traffic density (front) and a residential area (backyard).

Two IAQ monitoring campaigns were conducted in both studied classrooms, one in early 2020 (before COVID-19 pandemic) and the other in early 2021 (during COVID-19 pandemic). Thus, information on characteristics of nursery and primary schools and respective studied classrooms, as well as information on relevant activities, occupation periods, number of occupants, and potential sources of pollution were collected in each campaign. Accordingly, Table 1 summarises the main characteristics of each studied classroom, including children's age, floor, area, average occupancy, occupant density and occupancy periods.

Table 1: Summary of the main characteristics of each studied classroom.

\begin{tabular}{|c|c|c|c|c|c|c|c|}
\hline \multicolumn{2}{|c|}{ Classroom } & $\begin{array}{l}\text { Children's } \\
\text { age (years) }\end{array}$ & Floor & $\begin{array}{l}\text { Area } \\
\left(\mathrm{m}^{2}\right)\end{array}$ & $\begin{array}{c}\text { Average } \\
\text { occupancy }\end{array}$ & $\begin{array}{l}\text { Occupant density } \\
\left(\text { occupants } / \mathrm{m}^{2}\right)\end{array}$ & $\begin{array}{c}\text { Occupancy } \\
\text { period }\end{array}$ \\
\hline \multirow{2}{*}{ I07_A } & 2020 & \multirow[t]{2}{*}{ - } & \multirow{2}{*}{$\begin{array}{l}\text { Ground } \\
\text { floor }\end{array}$} & \multirow{2}{*}{40} & 20 & 0.50 & \multirow{2}{*}{$\begin{array}{c}9-12 \text { h; } \\
13 \text { h } 30- \\
17 \text { h } 15 \\
\end{array}$} \\
\hline & 2021 & & & & 16 & 0.40 & \\
\hline \multirow{2}{*}{ S07_B } & 2020 & $9-10$ & \multirow{2}{*}{$\begin{array}{l}2 \text { nd } \\
\text { floor }\end{array}$} & \multirow{2}{*}{40} & 18 & 0.45 & \multirow{2}{*}{$9-18 h$} \\
\hline & 2021 & $8-9$ & & & 18 & 0.45 & \\
\hline
\end{tabular}

Both classrooms (I07_A and S07_B) presented similar school timetables between the two studied periods. Moreover, S07_B kept the same number of occupants between the two campaigns, while the occupant density decreased from 0.50 to 0.40 occupants $/ \mathrm{m}^{2}$ in the second campaign (2021) for I07_A. Furthermore, none of the studied classrooms had mechanical ventilation, whereby natural ventilation was adopted through opening the available windows and/or doors, with a notorious increase in the COVID-19 pandemic campaign. Cleaning activities were usually carried out by cleaning staff more than once a day (during and at the end of the occupancy period) in both studied classrooms. However, the COVID-19 preventive measures implemented in 2021 promoted personal and environmental hygiene throughout the day, through the regular use of hand sanitiser and the 
cleaning of surfaces and shared objects/toys in the classrooms using alcohol-based disinfectants.

In both indoor air quality campaigns (before and during COVID-19 pandemic), Total VOC (TVOC) continuous monitoring (1 minute log) was performed using two researchgrade instruments - HazScanner Model IEMS and GrayWolf AndvanceSence BE - for a minimum period of four consecutive days (two weekdays followed by the weekend). The instruments were deployed precisely in the same place in both campaigns on a table or a shelf, usually near a wall or in the centre of the studied classrooms at about the height of the children's breathing.

After each IAQ monitoring campaign, data were collected at the two studied classrooms for analysis. Continuous measurements logged each minute allowed to plot the TVOC time series using 1 minute values and perform the TVOC hourly mean daily profile, the comparison with reference limit values, and the descriptive statistical analysis using 1 hour mean. In addition, two average periods were considered for the analysis, namely: (i) an average all day period (hourly means of all weekdays); and (ii) an average occupancy period (hourly means during occupancy periods considering the school timetable, which corresponded to children's exposure period). Normality was assessed using Shapiro-Wilk Test, and the significance of the differences between TVOC concentrations in the two campaigns was assessed using Wilcoxon Signed Rank Test.

TVOC concentrations were compared with the Portuguese legislated limit value [7] considering as exceedance if the daily maximum of 8 hours running means was above $1,200 \mu \mathrm{g} / \mathrm{m}^{3}\left(600 \mu \mathrm{g} / \mathrm{m}^{3}\right.$, plus $100 \%$ of margin of tolerance in the absence of a mechanical ventilation system working in the classrooms).

All statistical analyses were performed using the $\mathrm{R}$ software version 4.0.5, and the statistical significance level was set at 0.05 .

\section{RESULTS AND DISCUSSION}

Fig. 1 presents the TVOC time series profiles for S07_B and I07_A before and during COVID-19 pandemic.

As can be seen in Fig. 1, the highest TVOC concentrations were found on weekdays during occupancy (more evident during the COVID-19 pandemic period), while nonoccupancy and weekends showed almost constant baseline concentrations (below the detection limit). In addition, those profiles are in accordance with other studies carried out in the same type of classrooms and schools of this study [8]-[10].

Thus, the daily mean scenario was considered for further analyses, and the TVOC hourly mean daily profile, including both classrooms and both periods (before and during COVID19 pandemic) were plotted in Fig. 2.

Table 2 summarises the main statistical parameters (minimum, maximum, mean, median and standard deviation) of the TVOC hourly mean data for each studied classroom (I07_A and S07_B) before and during COVID-19 pandemic, considering the entire period of weekdays $(24 \mathrm{~h})$ and the occupancy period. Also, the difference in TVOC concentrations from 2020 to 2021 in both classrooms were quantified and presented in Table 2 .

The reference Portuguese legislated limit value for TVOC $\left(1,200 \mu \mathrm{g} / \mathrm{m}^{3}\right)$ was exceeded during the occupancy period in the two studied classrooms (S07_B and I07_A) during COVID-19 pandemic. However, the TVOC reference limit value in both classrooms was never exceeded before the pandemic, although the highest concentrations were also found during the occupancy. The levels found may cause acute and/or chronic health effects for classroom occupants, especially children, thus a health risk assessment should be performed to evaluate both long-term and short-term exposure to TVOC high concentrations [8], [11]. 


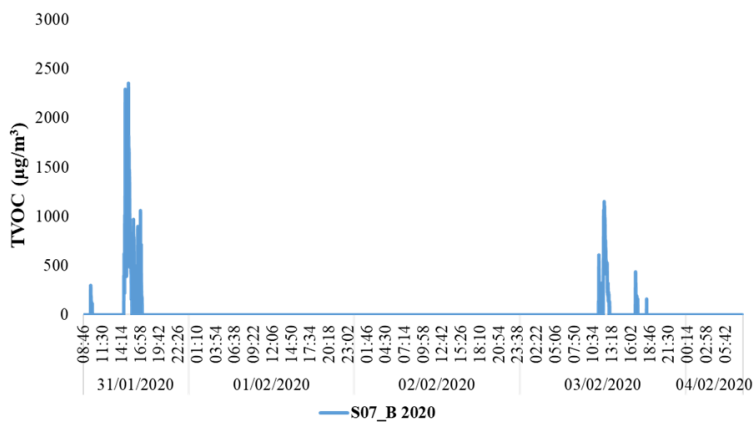

(a)

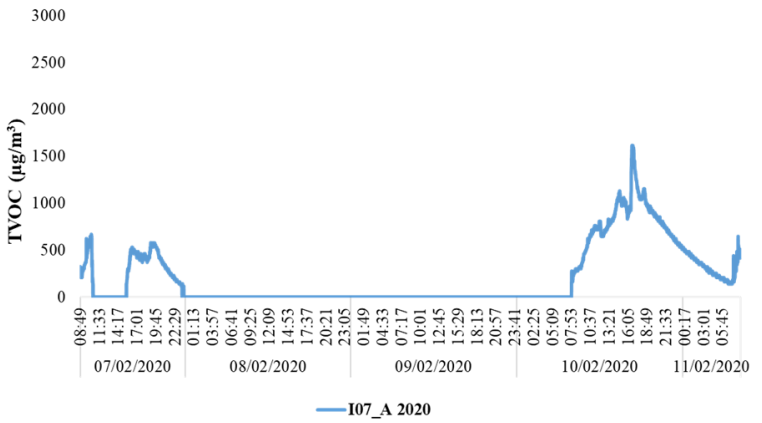

(b)

$$
25000
$$

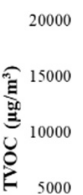

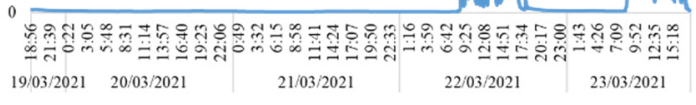

-S07_B 2021

(c)

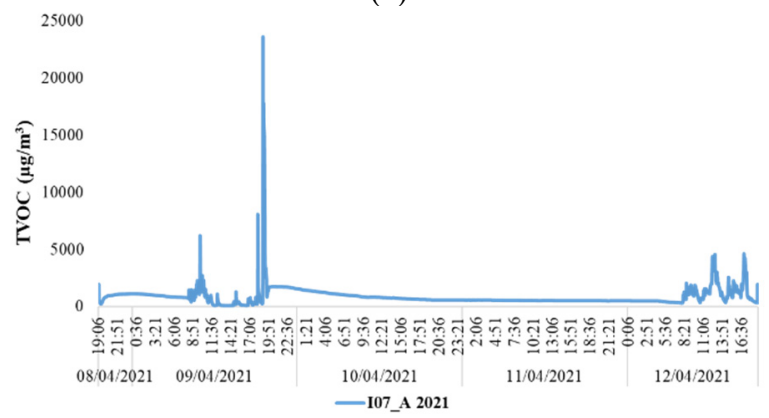

(d)

Figure 1: TVOC time series profiles considering 1 min mean for: (a) S07_B in 2020; (b) I07_A in 2020; (c) S07_B in 2021; and (d) I07_A in 2021. 


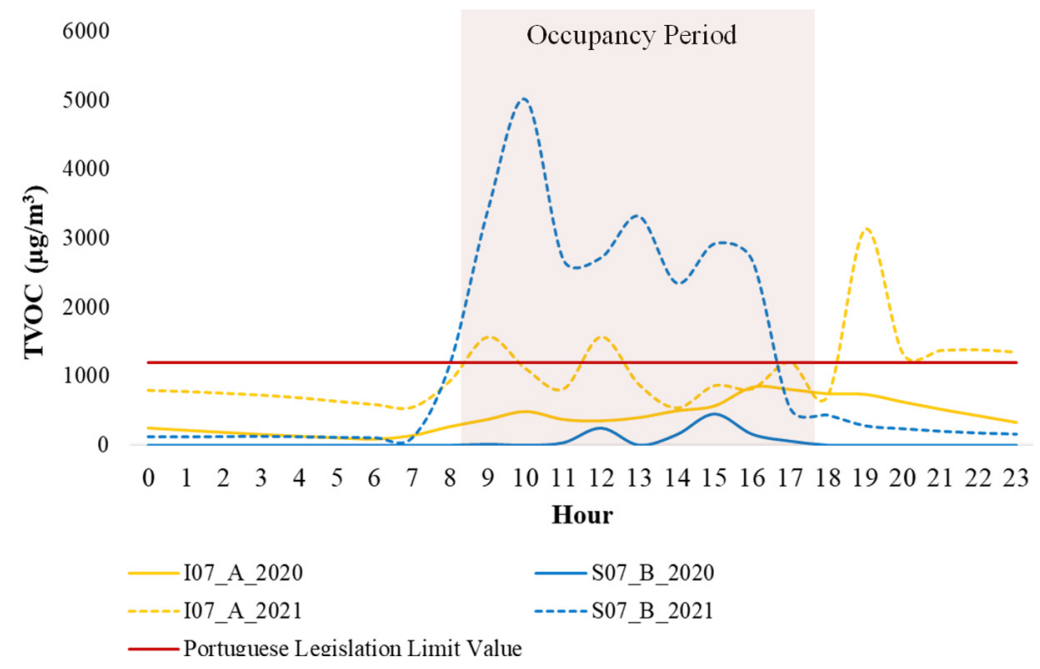

Figure 2: $\quad$ TVOC hourly mean daily profile for S07_B and I07_A before (2020) and during COVID-19 pandemic (2021) considering the Portuguese legislation reference limit value.

Table 2: Descriptive statistics of TVOC concentrations in the two studied classrooms (I07_A and S07_B) before and during COVID-19 pandemic, as well as the differences in the classrooms from 2020 to 2021, considering two periods (weekday and occupancy).

\begin{tabular}{|c|c|c|}
\hline & Weekday (24 h) & Occupancy period \\
\hline \multicolumn{3}{|c|}{ Classroom I07_A in 2020} \\
\hline Mean (SD) & $397(230)$ & $518(185)$ \\
\hline Median [Min, Max] & $369[82.1,836]$ & $484[348,836]$ \\
\hline \multicolumn{3}{|c|}{ Classroom I07_A in 2021} \\
\hline Mean (SD) & $1040(550)$ & $1040(354)$ \\
\hline Median [Min, Max] & $839[537,3130]$ & $878[537,1570]$ \\
\hline \multicolumn{3}{|c|}{ Difference in classroom I07_A } \\
\hline Mean (SD) & $647(495) *$ & $521(441) *$ \\
\hline Median [Min, Max] & $563[-27.4,2400]$ & $445[-19.9,1220]$ \\
\hline \multicolumn{3}{|c|}{ Classroom S07 B in 2020} \\
\hline Mean (SD) & $46.1(106)$ & $123(147)$ \\
\hline Median [Min, Max] & $0[0,443]$ & $58.5[0.962,443]$ \\
\hline \multicolumn{3}{|c|}{ Classroom S07_B in 2021} \\
\hline Mean (SD) & $1220(1480)$ & $2850(1170)$ \\
\hline Median [Min, Max] & $256[105,5010]$ & $2720[537,5010]$ \\
\hline \multicolumn{3}{|c|}{ Difference in classroom S07_B } \\
\hline Mean (SD) & $1170(1440) *$ & $2730(1200) *$ \\
\hline Median [Min, Max] & $256[105,5010]$ & $2520[479,5010]$ \\
\hline
\end{tabular}

Difference in classroom I07 A and difference in classroom S07 B correspond to the difference in TVOC concentrations from 2020 to 2021 for I07_A and S07_B respectively; ${ }^{*}$ statistically significant $(p$-value $<0.05)$. 
As stated above, the presence of high TVOC concentrations occurred mainly during occupancy periods either before or during COVID-19 pandemic. In the first case (before the pandemic), its occurrence seemed to be a result of typical children activities carried out in the classrooms associated with the use of paints and glues (mostly in S07_B), as well as with the children's hygiene, such as diaper change, where some products that emitted VOC may have been used (exclusively in I07_A). In turn, the constant application of COVID-19 preventive measures, such as the intensive and periodic cleaning of surfaces, objects and hands using alcohol-based sanitisers and disinfectants, seemed to be the main explanation for the concentrations found during the pandemic period. Besides, the typical children's activities carried out within classrooms before the pandemic, and which appear to be the main cause of the TVOC presence, were maintained in 2021, so they could also have contributed to TVOC concentrations. Moreover, a peak between 18:00 and 20:00 in I07_A during COVID-19 pandemic was detected (Figs 1(d) and 2), which seemed to be caused by a reinforced cleaning of all materials and toys using an alcohol-based solution, usually performed before the weekend.

According to the results shown in Table 2 , a statistically significant increase ( $p$-value $<0.05$ ) on TVOC concentrations from 2020 to 2021 were observed in the two studied classrooms for both average all day (mean difference: $647 \mu \mathrm{g} / \mathrm{m}^{3}$ and $1,170 \mu \mathrm{g} / \mathrm{m}^{3}$ for I07_A and S07_B, respectively) and average occupancy periods (mean difference: $521 \mu \mathrm{g} / \mathrm{m}^{3}$ and $2,730 \mu \mathrm{g} / \mathrm{m}^{3}$ for I07_A and S07_B, respectively). It is possible to observe a higher mean difference between the two periods for S07_B, which could be explained by the TVOC baseline concentration during the non-occupancy period being below the limit of detection before COVID-19 pandemic.

From a global perspective, one of the most common COVID-19 preventive measures the continued use of sanitisers and disinfectants - increased the TVOC concentrations in the two studied classrooms to unsafe levels, which were not achieved before the pandemic. Moreover, the increase on natural ventilation during the COVID-19 pandemic, was insufficient to disperse VOC to the levels registered in 2020.

Therefore, it should be considered the reduction of alcohol-based products for the disinfection of surfaces and materials since surface transmission is not thought to be a significant risk (although possible) [12]. At the same time, the increase of ventilation should be even more encouraged to reduce the risk of transmission of diseases such as COVID-19 through aerosols [13]. The promotion of cross ventilation when using VOC emitting products should be considered since it will allow not only to prevent the accumulation of VOC in the indoor air but also to reduce $\mathrm{CO}_{2}$ concentrations, which are usually above recommended thresholds in this type of classrooms, through a higher air change rate [14], [15].

\section{CONCLUSIONS}

As far as the author's knowledge goes, this was the first study quantifying the impact of COVID-19 preventive measures on TVOC concentration before and during COVID-19 pandemic in one nursery and one primary school.

The present study concluded that the more intense use of VOC-emitting compounds for personal (hands) and environmental (surfaces) disinfection, suggested by the COVID-19 preventive measures for reopening schools, has caused a statistically significant increase ( $p$-value $<0.05$ ) in the TVOC concentrations in the studied classrooms, from both nursery and primary schools, when compared to a period before the pandemic. That increment was more evident during occupancy periods, often exceeding the reference limit value in the Portuguese legislation, which may lead occupants (especially children) to be exposed to harmful levels of air pollution that may cause acute and/or chronic health effects. 
Therefore, disinfection measures should be balanced with proper ventilation, namely cross ventilation, which allows not only to reduce VOC but also to prevent the accumulation of exhaled air and, thus, reduce the risk of COVID-19 infection by aerosols.

As future work, it is recommended to perform an individual VOC identification and extend this analysis to more schools, classrooms, and pollutants. Also, it should be considered the performance of a health risk assessment to evaluate both long-term and short-term exposure to TVOC high concentrations. In addition, a balance in the spread of COVID-19 preventive measures are crucial, so it is also important to quantify their impact in other indoor air pollutants (such as $\mathrm{CO}_{2}$ and $\mathrm{PM}$ ).

\section{ACKNOWLEDGEMENTS}

This work was financially supported by: Base Funding - UIDB/00511/2020 of the LEPABE - funded by national funds through FCT/MCTES (PIDDAC); Project PTDC/EAMAMB/32391/2017, funded by FEDER funds through COMPETE2020 - POCI and by national funds (PIDDAC) through FCT/MCTES.

\section{REFERENCES}

[1] Morawska, L. et al., Airborne particles in indoor environment of homes, schools, offices and aged care facilities: The main routes of exposure. Environment International, 108, pp. 75-83, 2017.

[2] Annesi-Maesano, I. et al., Indoor air quality and sources in schools and related health effects. Journal of Toxicology and Environmental Health, Part B, 16(8), pp. 491-550, 2013.

[3] Paterson, C.A. et al., Indoor $\mathrm{PM}_{2.5}$, VOCs and asthma outcomes: A systematic review in adults and their home environments. Environmental Research, 202, 111631, 2021.

[4] DGS, Referencial Escolas: Controlo da transmissão de COVID-19 em contexto escolar. Direção Geral da Saúde: Lisbon, Portugal, 2020.

[5] WHO, Considerations for school-related public health measures in the context of COVID-19: Annex to considerations in adjusting public health and social measures in the context of COVID-19, 14 September 2020. World Health Organization, United Nations Children's Fund (UNICEF) \& United Nations Educational Scientific and Cultural Organization, 2020. https://apps.who.int/iris/handle/10665/334294.

[6] EPA, Technical overview of volatile organic compounds. United States Environmental Protection Agency, 2017. https://www.epa.gov/indoor-air-quality-iaq/technicaloverview-volatile-organic-compounds\#3. Accessed on: 7 Aug. 2021.

[7] Portaria no. 353-A/2013, Ministérios do Ambiente, Odenamento do Território e Energia, da Saúde e da Solidariedade, Emprego e Segurança Social - Diário da República - 1 a Série, No. 253(9), pp. 6644(2)-6644, 2013.

[8] Branco, P.T.B.S. et al., Children's exposure to indoor air in urban nurseries: Part II: Gaseous pollutants' assessment. Environmental Research, 142, pp. 662-670, 2015.

[9] Nunes, R.A.O. et al., Gaseous pollutants on rural and urban nursery schools in Northern Portugal. Environmental Pollution, 208, pp. 2-15, 2016.

[10] Sá, J. et al., Evaluation of low-cost mitigation measures implemented to improve air quality in nursery and primary schools. International Journal of Environmental Research and Public Health, 14(6), p. 585, 2017.

[11] Sexton, K. et al., Children's exposure to volatile organic compounds as determined by longitudinal measurements in blood. Environmental Health Perspectives, 113(3), pp. 342-349, 2005. 
[12] Zhang, N. et al., Evidence for lack of transmission by close contact and surface touch in a restaurant outbreak of COVID-19. Journal of Infection, 83(2), pp. 207-216, 2021.

[13] Fermo, P. et al., Improving indoor air quality through an air purifier able to reduce aerosol particulate matter (PM) and volatile organic compounds (VOCs): Experimental results. Environmental Research, 197, 111131, 2021.

[14] Alonso, A. et al., Effects of the COVID-19 pandemic on indoor air quality and thermal comfort of primary schools in winter in a Mediterranean climate. Sustainability, 13(5), p. 2699, 2011.

[15] Jones, E. et al., Healthy schools: risk reduction strategies for reopening schools. Harvard TH Chan School of Public Health Healthy Buildings Program, 2020. 